SHORT COMMUNICATION

\title{
Synthesis of Aramids by Polycondensation of Aromatic Dicarboxylic Acids with Aromatic Diamines Containing Ether Linkages
}

\author{
By Yu SHoJI, Katsuhisa MIZoguCHI, and Mitsuru UEDA*
}

\author{
KEY WORDS: Polycondensation / Aramid / Aromatic Dicarboxylic Acids / Aromatic Diamines /
}

Wholly aromatic polyamides (aramids) such as $\operatorname{poly}(m$-phenyeleneisophthalamide) and poly( $p$-phenyleneterephthalamide) are one of the super engineering plastics, and widely used as fibers with excellent tensile and thermal properties. ${ }^{1-4}$ Aramids are prepared by the solution or interfacial polycondensation of aromatic diacid chlorides with aromatic diamines because of low reactivity of aromatic diamines toward aromatic dicarboxylic acids. Furthermore, some of them are infusible and a melt processing is not possible. ${ }^{5}$ An acid chloride method, however, is not an atom economical one because hydrogen chloride, which has a larger molecular weight than that of water, is produced as a side product. Moreover, a very reactive diacid chloride must be prepared from a dicarboxylic acid with thionyl chloride or other chlorinating agents, and must be stored in a refrigerator under a dry condition to avoid its hydrolysis. Thus, the direct synthesis of aramids from aromatic dicarboxylic acids and aromatic diamines is important and straightforward.

Only one report has been published on the direct synthesis of polyamides using the aromatic diamines. ${ }^{6}$ Holmer and coworkers studied the melt polycondensation of $4,4^{\prime}$-methylenedianiline with aliphatic dicarboxylic acids at around $280^{\circ} \mathrm{C}$ under reduced pressure, and reported that high molecular weight polyamides were obtained by using the aliphatic dicarboxylic acids with long methylene units such as nonanedioic acid and decanedioic acid. They also described that some diamines such as $4,4^{\prime}$ oxydianiline and 4,4'-isopropylidenedianiline were degraded in the melt systems used. These findings suggested that some aramids without decomposition would be prepared by a direct polycondensation method.

As the first step for a direct synthesis of aramids, we investigated the synthesis of aramids from aromatic dicarboxylic acids and aromatic diamines containing ether linkages which increase the mobility of polymer chains, and decrease the glass transition temperatures $\left(T_{\mathrm{g}} \mathrm{s}\right)$ and melting points $\left(T_{\mathrm{m}} \mathrm{s}\right)$ of the resulting aramids.

Here we report the successful direct synthesis of aramids by the polycondensation of aromatic dicarboxylic acids with aromatic diamines containing ether linkages.

\section{MODEL REACTION}

Prior to the synthesis of aramids, the model reaction of benzoic acid (1) with $4,4^{\prime}$-oxydianiline (2) was carried out in a melt state to investigate the feasibility on the direct synthesis of aramids (Scheme 1). Considering the sublimation of $\mathbf{1}$, a small excess amount of $\mathbf{1}$ to $\mathbf{2}$ was used. The results are summarized in Table I. All the reactions proceeded at first in homogeneous states and then became heterogeneous after 2 or $3 \mathrm{~h}$ depending on the reaction temperature. A quantitative yield of the desired diamide, 4,4'oxydibenzanilide (3) is obtained at $230^{\circ} \mathrm{C}$ for $5 \mathrm{~h}$. It is confirmed that an aromatic amine reacts with an aromatic acid in the range of temperature of $200-230^{\circ} \mathrm{C}$.

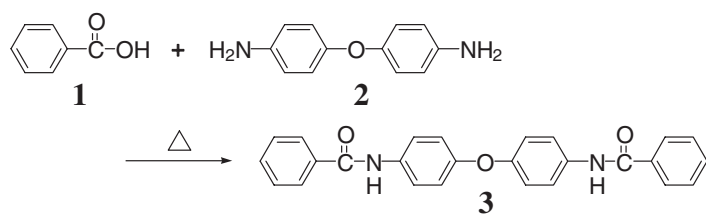

Scheme 1. Synthesis of diamide $\mathbf{3}$ from $\mathbf{1}$ and $\mathbf{2}$.

Table I. Synthesis of diamide $3^{a}$

\begin{tabular}{ccc}
\hline Run No. & $\begin{array}{c}\text { Conditions } \\
\text { Temp. }\left[{ }^{\circ} \text { C]/Reaction time }[\mathrm{h}]\right.\end{array}$ & $\begin{array}{c}\text { Yield } \\
{[\%]}\end{array}$ \\
\hline 1 & $200 / 2$ & 58 \\
2 & $200 / 5$ & 90 \\
3 & $230 / 5$ & 97 \\
\hline
\end{tabular}

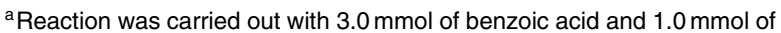
$4,4^{\prime}$-oxydianiline.

\section{SYNTHESIS OF ARAMIDS}

On the basis of the model reaction, the following aramids which were expected to have low melting or low glass transition temperatures due to the presence of flexible ether units were selected. The polycondensations of aromatic dicarboxylic acids, i.e., 4,4'-hexafluoroisopropylidene-bis(benzoic

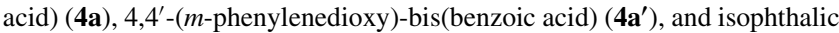
acid $\left(\mathbf{4 a}^{\prime \prime}\right)$ with aromatic diamines, i.e., 4,4'-hexafluoroisopropylidenebis $\left(p\right.$-phenyleneoxy)dianiline (5b), 4, $4^{\prime}$ - $\left(m\right.$-phenylenedioxy)dianilne $\left(\mathbf{5} \mathbf{b}^{\prime}\right)$, and $3,4^{\prime}$-oxydianiline $\left(\mathbf{5} \mathbf{b}^{\prime \prime}\right)$ were carried out at various conditions under nitrogen (Scheme 2). The results are summarized in Table II. The temperature of polymerization was carefully increased in three or four steps: (i) above the melting point of diamines to initiate the reaction with dicarboxylic acids, (ii) $170-200^{\circ} \mathrm{C}$ for oligomer formation, and (iii) $300{ }^{\circ} \mathrm{C}$ for increasing molecular weights of aramids. The polycondensation proceeded in the melt state at the first step and then solid state to yield the desired aramids 6 with high number-average molecular weights $\left(M_{\mathrm{n}}\right)$ up to 55,000. Although diamines $\mathbf{5}$ have a similar ether structure to diamine 2, aramids with high molecular weights are obtained without degradation of $\mathbf{5}$, which is a different result described in the introduction.

The structure of aramids was characterized by IR and ${ }^{1} \mathrm{H}$ NMR spectroscopies. The IR spectra showed characteristic of the N-H and the $\mathrm{C}=\mathrm{O}$ stretchings of amino and amide carbonyl groups at 3429 and $1658 \mathrm{~cm}^{-1}$, respectively. Figure 1 shows the ${ }^{1} \mathrm{H}$ NMR spectrum of aramid

Department of Organic \& Polymeric Materials, Graduate School of Science \& Engineering, Tokyo Institute of Technology, 2-12-1-H120, Ookayama, Meguro-ku, Tokyo 152-8552, Japan

*To whom correspondence should be addressed (E-mail: ueda.m.ad@m.titech.ac.jp). 


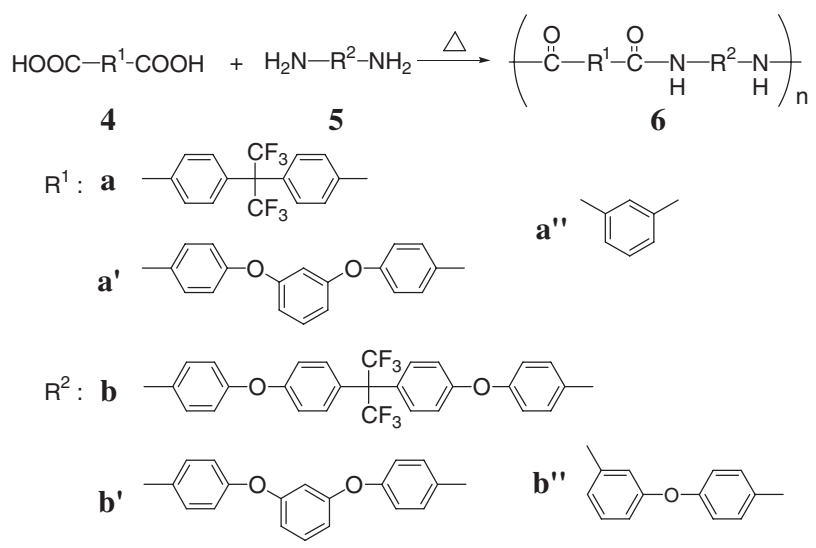

Scheme 2. Synthesis of aramids 6 .

Table II. Synthesis of aramids $6^{\mathrm{a}}$

\begin{tabular}{llcrrrr}
\hline $\mathrm{R}^{1}$ & $\mathrm{R}^{2}$ & $\begin{array}{c}\text { Condition } \\
\text { Temp. }\left[{ }^{\circ} \mathrm{C}\right] / \text { Time }[\mathrm{h}]\end{array}$ & $\begin{array}{r}\text { Yield } \\
{[\%]}\end{array}$ & $M_{\mathrm{n}}{ }^{\mathrm{b}}$ & $M_{\mathrm{w}}{ }^{\mathrm{b}}$ & $\mathrm{PDI}^{\mathrm{b}}$ \\
\hline $\mathbf{a}$ & $\mathbf{b}$ & $180 / 1 \rightarrow 200 / 2 \rightarrow 300 / 7$ & 76 & 38,000 & 80,000 & 2.1 \\
$\mathbf{a}$ & $\mathbf{b}^{\prime}$ & $130 / 0.5 \rightarrow 170 / 0.5 \rightarrow 200 / 2 \rightarrow 300 / 7$ & 79 & 52,000 & 169,000 & 3.2 \\
$\mathbf{a}^{\prime}$ & $\mathbf{b}^{\prime}$ & $130 / 0.5 \rightarrow 170 / 0.5 \rightarrow 200 / 2 \rightarrow 300 / 7$ & 77 & 34,000 & 71,000 & 2.1 \\
$\mathbf{a}^{\prime \prime}$ & $\mathbf{b}^{\prime}$ & $130 / 0.5 \rightarrow 170 / 0.5 \rightarrow 200 / 2 \rightarrow 300 / 7$ & 97 & 55,000 & 110,000 & 2.1 \\
$\mathbf{a}^{\prime \prime}$ & $\mathbf{b}^{\prime \prime}$ & $100 / 1 \rightarrow 200 / 2 \rightarrow 300 / 7$ & 91 & 37,000 & 116,000 & 3.1 \\
\hline
\end{tabular}

apolycondensation was carried out with $0.5 \mathrm{mmol}$ of each dicarboxylic acid 4 and diamines 5 . ' Determined by GPC (DMF, PSt standard).

$\mathbf{6} \mathbf{a b}^{\prime}$, in which a doublet signal $\mathbf{2}$ assignable to the $o$-aromatic protons next to the amide bond is observed at $8.03 \mathrm{ppm}$, and the characteristic amide protons at $10.4 \mathrm{ppm}$ appear. Assignments of other protons are depicted in Figure 1. Furthermore, the structures of aramids were also confirmed by elemental analysis. These findings clearly supported the formation of the desired aramids 6.

The thermal properties of aramids 6 were examined by thermogravimetry (TG) and differential scanning calorimetry (DSC) (Table III). Aramids 6 show an excellent thermal stability, and the $5 \mathrm{wt} \%$ loss temperatures for polymers are higher than $450^{\circ} \mathrm{C}$ under a nitrogen atmosphere. The $T_{\mathrm{g}} \mathrm{s}$ are above $180^{\circ} \mathrm{C}$. Faint yellow, transparent, and strong films could be obtained by casting from the NMP solutions of aramids 6 .

In summary, we have found that aramids with high molecular weights can be prepared by the direct polycondensation of aromatic dicarboxylic acids and diamines containing ether linkages. This method is applicable for the synthesis of aramids with $T_{\mathrm{g}} \mathrm{s}$ up to around $250^{\circ} \mathrm{C}$.

Electronic Supporting Information Available: Syntheses and characterization of model compound 3 and polyamide $6 \mathrm{ab}^{\prime}$. This material is available via the Internet at http://www.spsj.or.jp/c5/pj/pj.htm
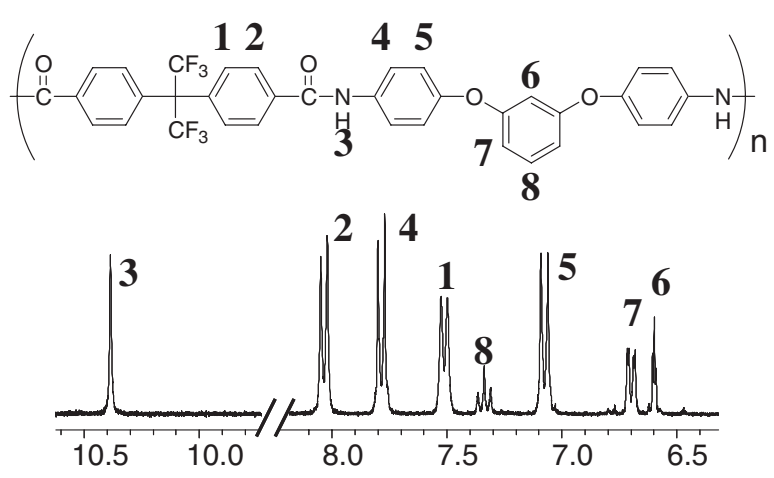

Figure 1. The ${ }^{1} \mathrm{H}$ NMR spectrum of aramid $\mathbf{6} \mathbf{a b}^{\prime}$.

Table III. Thermal properties of aramids 6

\begin{tabular}{cccc}
\hline polymer & $T_{\mathrm{g}}\left[{ }^{\circ} \mathrm{C}\right]^{\mathrm{a}}$ & $T_{\mathrm{m}}\left[{ }^{\circ} \mathrm{C}\right]^{\mathrm{a}}$ & $\begin{array}{c}T_{\mathrm{d}}\left[{ }^{\circ} \mathrm{C}\right]^{\mathrm{b}} \\
5 \mathrm{wt} \% \text { loss }\end{array}$ \\
\hline $\mathbf{6 a b}$ & 250 & - & 460 \\
$\mathbf{6} \mathbf{a b}^{\prime}$ & 235 & - & 460 \\
$\mathbf{6 a}^{\prime} \mathbf{b}^{\prime}$ & 180 & 300 & 465 \\
$\mathbf{6 a}^{\prime \prime} \mathbf{b}^{\prime}$ & 210 & 340 & 465 \\
$\mathbf{6 a}^{\prime \prime} \mathbf{b}^{\prime \prime}$ & 235 & - & 445 \\
\hline
\end{tabular}

${ }^{\mathrm{a}}$ Measured by DSC at a heating rate of $10^{\circ} \mathrm{C} / \mathrm{min}$. ${ }^{\mathrm{b}}$ Measured by TG at a heating rate of $10^{\circ} \mathrm{C} / \mathrm{min}$.

Received: February 19, 2008 Accepted: April 21, 2008 Published: June 18, 2008

\section{REFERENCES}

1. J. Preston, "Encyclopedia of Polymer Science and Engineering," H. F. Mark, N. M. Bikales, C. G. Overberger, G. Menges, and J. I. Kroschwitz, Ed., John-Wiley \& Sons, New York, 1988, Vol. 11, p 381.

2. L. Vollbracht, "Comprehensive Polymer Science," G. C. Eastmond, A. Ledwith, S. Russo, and P. Sigwalt, Ed., Pergamon Press, Oxford, 1989, Vol. 5, p 375.

3. R. J. Gaymans, "Synthetic Methods in Step-Growth Polymers," M. E. Rogers and T. E. Long, Ed., John-Wiley \& Sons, New York, 2001, p 57.

4. W. R. Sorenson, F. Sweeny, and T. W. "Cambell, Preparative Methods of Polymer Chemistry," John-Wiley \& Sons, New York, 2003, p 135.

5. P. W. Morgan, "Condensation Polymers: By interfacial and Solution Methods," Interscience, New York, 1965, p 190.

6. D. A. Holmer, O. A. Pickett, Jr., and J. H. Saunders, J. Polym. Sci., A-1, 10, 1547 (1972). 